\title{
ANALYSIS OF ISLAMIC ORGANIZATIONAL CULTURE IN FOSTERING ORGANIZATIONAL INNOVATION ON RABBANI HOLDING, BANDUNG
}

\author{
Ratih Purbasari \\ Department of Business Administration Science \\ Faculty of Politics and Social Science, Padjadjaran University \\ Email : klik_ratih@yahoo.co.id ratih.purbasari@unpad.ac.id \\ Nurillah Jamil Achmawati Novel \\ Graduate Program - SBM ITB \\ Email : novel.nurillah@yahoo.com
}

\begin{abstract}
This study raised concerns about the Islamic culture on Rabbani Holding, which has been widely known as a company that produces products of Islamic fashion in Bandung and has received awards from various institutions. Nevertheless, Rabbani keep innovating organization driven by company dynamic and its cultural values. Research on islamic culture at a fashion company area is still rare in Bandung due to fashion business itself has been just rapidly growing in recent years. Thus, it becomes very interesting subject to study, especially if associated with organizational innovation.

This study used qualitative research methods through extracting information (interviews) in depth, literature, and field observations. Data processed by the coding technique and analyzed descriptively. The results showed that Islamic organizational culture in Rabbani Holding has been implemented consistently and continously evolving. Islamic culture which has been applied in Rabbani is fundamental in driving performance in all its business functions, where its culture consists of consumer focus, employee focus, quality focus and organization focus which includes the core values of Rabbani organizational innovation.
\end{abstract}

Keywords : Organizational Culture, Islamic Organizational Culture, Organizational Innovation.

\section{ANALISIS BUDAYA ORGANISASI ISLAMI DALAM MENDORONG INOVASI ORGANISASI PADA RABBANI HOLDING, BANDUNG}

\begin{abstract}
ABSTRAK
Penelitian ini mengangkat permasalahan mengenai kondisi budaya Islam pada perusahaan Rabbani, sebagai perusahaan yang menghasilkan produk-produk fashion Islami di Kota Bandung dan telah menerima penghargaan dari berbagai instansi. Meskipun demikian, Rabbani tetap melakukan inovasi organisasi yang didorong oleh kondisi perusahaan yang dinamis dan nilai budaya yang ada di organisasinya. Penelitian mengenai budaya Islami pada sebuah perusahaan fashion masih jarang dilakukan di Bandung dikarenakan fashion Islami baru berkembang pesat beberapa tahun belakangan. Sehingga, topik ini menjadi sangat menarik untuk diteliti, terutama jika dikaitkan dengan inovasi organisasi. Penelitian ini menggunakan metode penelitian kualitatif melalui penggalian informasi (wawancara) secara mendalam, studi pustaka, dan observasi lapangan. Data diolah dengan teknik koding dan dianalisis secara deskriptif. Hasil penelitian menunjukkan penerapan budaya organisasi Islam pada Rabbani telah dilaksanakan dengan konsisten dan terus mengalami perkembangan. Budaya Islam yang diterapkan Rabbani menjadi dasar utama yang menggerakan kinerja di semua fungsi bisnis Rabbani, dimana budaya tersebut terdiri dari fokus konsumen, fokus karyawan dan fokus kualitas dan fokus organisasi yang mencakup nilai-nilai utama dari inovasi organisasi Rabbani.
\end{abstract}

Kata kunci : budaya organisasi Islam, budaya organisasi, inovasi organisasi.

Jurnal AdBispreneur Vol. 1, No. 1, April 2016 Hal. 27-37 


\section{PENDAHULUAN}

Perkembangan dunia fashion kini mencapai titik yang mengesankan, didukung dengan kemajuan teknologi informasi yang memperluaskan pengetahuan tentang berbagai macam fashion. Terutama adalah trend fashion muslim yang ditandai dengan berkembangnya komunitas "hijabers", toko-toko busana muslim seperti Rabbani, Shafira, Zoya, dan lain-lain. Bahkan berkembang pula penjualan busana muslim melalui media online seperti www.zoya.co.id, www.media.shafira.com, www.rabbani.co.id dan lain-lain.

Maka dari itu, fashion muslim pun mengalami perkembangan dengan inovasiinovasi yang lebih menarik dan modern, yaitu suatu gagasan, praktek, atau benda yang dianggap/dirasa baru oleh individu atau kelompok masyarakat (Rogers:1983). Inovasi fashion muslim ini juga mengalami beberapa tahap inovasi seperti adanya kesadaran akan inovasi, keinginan untuk berinovasi, keputusan berinovasi, mencoba inovasi dan mengadopsi inovasi tersebut.

Busana muslim adalah ciri khas dari kaum muslim, dimana merupakan kewajiban menutupi anggota-anggota tubuh sebagai suatu syariat dan salah satu bentuk akhlaq muslim dan perilaku Islam. Dengan demikian, dalam busana muslimah sangat erat hubungannya dengan nilainilai Islam yang kemudian tercerminkan dalam bentuk budaya Islam. Sehingga, busana muslim harus sejalan dengan nilai serta budaya Islam.

Salah satu toko busana muslim yang berkembangnya sangat pesat sejak didirikan pada tahun 1994 adalah perusahaan Rabbani. Perusahaan ritail busana muslim dengan tagline Professor Kerudung Indonesia ini ingin merubah paradigma masyarakat bahwa mengenakan busana muslim itu kurang modis. Sehingga, perusahaan ini mengeluarkan produk-produk dengan inovasi yang beragam dengan tidak kurang dari 10 kategori produk. Didukung pula dengan misi perusahaan Rabbani yaitu "Menshibghohkan Fashion Dunia dengan
Syariah." Sehingga dapat kita lihat bahwa misi yang dibawa oleh perusahaan ini "syariah".

Dari hal-hal yang telah diuraikan di atas, banyak hal menarik terkait budaya islam serta perkembangan inovasi busana muslim. Terutama di Indonesia yang sedang mengalami puncak trend busana muslim, sehingga banyak bermunculan komunitas, perusahaan maupun tutorial yang terkait busana muslim. Dari alasan menarik di atas maka kami berminat untuk melakukan penelitian dengan judul,"Analisis Budaya Organisasi Islam Dalam Mendorong Inovasi Organisasi Pada Rabbani Holding, Bandung."

\section{TINJAUAN PUSTAKA}

\section{Budaya Organisasi}

Menurut Schein (1985), budaya organisasi mengacu ke suatu sistem makna bersama dianut oleh anggota-anggota yang membedakan organisasi itu terhadap organisasi-organisasi lain.

Menurut Robbins (1990), Budaya organisasi sering dimaknakan sebagai filosofi dasar yang memberikan arahan bagi kebijakan organisasi dalam pengelolaan karyawan dan nasabah.

Robbins (2001), Budaya organisasi merupakan suatu sistem pemaknaan bersama dibentuk oleh para warganya yang sekaligus menjadi pembeda dengan organisasi lain.

\section{Hubungan Islam dengan Budaya}

Menurut Hegel, keseluruhan karya sadar insani yang berupa ilmu, tata hukum, tatanegara, kesenian, dan filsafat tak lain daripada proses realisasidiri dari roh ilahi.

Menurut Pater Jan Bakker, dalam bukunya "Filsafat Kebudayaan" menyatakan bahwa tidak ada hubungannya antara agama dan budaya, karena menurutnya, bahwa agama merupakan keyakinan hidup rohaninya pemeluknya, sebagai jawaban atas panggilan ilahi. 
Menurut Drs. Heddy S. A. Putra, MA bahwa agama merupakan salah satu unsur kebudayaan.

\section{Budaya Islami}

Undang-undang Dasar Negara Indonesia, pasal 32

Dalam penjelasan UUD pasal 32, disebutkan: "Usaha kebudayaan harus menuju ke arah kemajuan adab, budaya dan persatuan, dengan tidak menolak bahan-bahan baru dari kebudayaan asing yang dapat memperkembangkan atau memperkaya kebudayaan bangsa sendiri, serta mempertinggi derajat kemanusiaan bangsa Idonesia.“

\section{Karateristik Budaya Organisasi}

Undang-undang Dasar Negara Indonesia, pasal 32

Dalam penjelasan UUD pasal 32, disebutkan: "Usaha kebudayaan harus menuju ke arah kemajuan adab, budaya dan persatuan, dengan tidak menolak bahan-bahan baru dari kebudayaan asing yang dapat memperkembangkan atau memperkaya kebudayaan bangsa sendiri, serta mempertinggi derajat kemanusiaan bangsa Idonesia.“

Dari situ, Islam telah membagi budaya menjadi tiga macam :

Pertama : Kebudayaan yang tidak bertentangan dengan Islam. Seperti; kadar besar kecilnya mahar dalam pernikahan, di dalam masyarakat Aceh, umpamanya, keluarga wanita biasanya, menentukan jumlah mas kawin sekitar 50-100 gram emas.

Kedua : Kebudayaan yang sebagian unsurnya bertentangan dengan Islam. Contoh yang paling jelas, adalah tradisi Jahiliyah yang melakukan ibadah haji dengan cara-cara yang bertentangan dengan ajaran Islam, seperti lafadh "talbiyah" yang sarat dengan kesyirikan, thowaf di Ka'bah dengan telanjang.
Ketiga : Kebudayaan yang bertentangan dengan Islam. Seperti, budaya "ngaben" yang dilakukan oleh masyarakat Bali.

\section{Karakteristik Budaya Organisasi}

Robbins (2001) memberikan 7 (tujuh) karakteristik budaya organisasi sebagai berikut:

1. Inovasi dan keberanian mengambil risiko ( Inovation and risk taking).

2. Perhatian terhadap detail (Attention to detail).

3. Berorientasi pada hasil (Outcome Orientation).

4. Berorientasi pada manusia (People Orientation)

5. Berorientasi pada tim (Team Orientation).

6. Agresif (Aggresiveness).

7. Stabil (Stability)

\section{Karakteristik Budaya Organisasi Islam}

Berdasarkan Abdul hakim (2012), karakteristik budaya organisasi islam terdiri dari:

a. "Smiling: To create the atmosphere of attention.

b. Greetings: To create welfare atmosphere.

c. Friendship: Good relationship among the employees both managers and staffs.

d. Helping among the others, having good cooperation.

e. Never telling a lie

f. Discipline: Using the time as well as possible. “

Karakteristik di ats merupakan sistem nilai yang di ambil dan dikembangkan dari Al-quran dan Hadist yang di praktekan dalam kehidupan sehari-hari.

\section{Inovasi Organisasi}

Pendapat Lam dalam Draft (1978); Damunpour (1996) dalam Alice Lam bahwa general. sense, the term "organizational innovation" refer. the creation or adoption of 
an idea or behavior new to the organization Inovasi organisasi dimaksudkan sebagai penciptaan atau adopsi ide atau perilaku baru ke dalam organisasi. Menurut pendapat ini terdapat tiga teori tentang inovasi organisasi yaitu :

a. Teori Desain Organisasi (Organizational Design Teories)

Teori ini memfokuskan pada hubungan anima bentuk struktur dan kecenderungan organisasi untuk berinovasi atau untuk menentukan dampak variabel struktur organisasi pada produk atau proses inovasi.

b. Teori Kognisi dan Organisasi Pembelajaran

Teori ini memfokuskan pada proses lingkup yang kecil tentang bagaimana organisasi mengembangkan ide-ide baru untuk memecahkan masalah. Teori Kognisi dan Organisasi Pembelajaran

\section{c. Organizational Change dan Adaption}

Teori melandaskan pada penciptaan bentuk organisasi baru dan menekankan pada kemakmuran dan menyesuaikan dengan pergeseran lingkungan radikal dan perubahan teknologi dan apakah perubahan organisasi terjadi secara mendasar pada tingkat populasi seleksi dan inovasi dipertimbangkan sebagai kapabilitas untuk merespon perubahan dalam lingkungan eksternal yang akan mempengaruhi dan membentuknya.

Pengelompokkan Inovasi Organisasi menurut Schumann, Jr, et al , (1994:9) Inovasi dikelompokkan berdasarkan dua dimensi, yaitu berdasarkan bidang inovasi dan dampaknya terhadap organisasi. Berdasarkan bidangnya, inovasi organisasi terdiri dari:

1. Inovasi Produk. Pendapat ini menyatakan bahwa "product innovation involving the function provided to customer (external or internal) of the form of function takes." Inovasi produk melibatkan fungsi-fungsi yang disediakan untuk pelanggan baik eksternal maupun internal alam bentuk fungsi yang dapat berguna bagi pelanggan.

2. Inovasi proses. "Processed innovation are those that involve the way a product is developed, produced and provided and involved the interaction people with thing"

Inovasi proses melibatkan cara suatu produk dikembangkan, diproduksi dan disediakan serta melibatkan interaksi manusia dan barang. Contoh inovasi proses ini adalah pengembangan proses pengolahan, sistem distribusi dan pengembangan produk.

3. Inovasi prosedur. "Procedure innovation ate those that involve the way in wmeh product and prosesses are in into the operation of the organization". Inovasi produk melibatkan cara produk dan proses diintegrasikan dalam pelaksanaan organisasi. Contohnya, pengembangan metode pemasaran. metode administrasi dan syarat-syarat penjualan. Inovasi prosedur melibatkan cara manusia berinteraksi dengan orang lain.

Dimensi kedua inovasi menurut Schumann, Jr, et al, (1994:1114) adalah kelas inovasi yang mencerninkan dampak inovasi terhadap organisasi. Menurut kelasnya, inovasi terbagi menjadi tiga yaitu:

1. Inovasi Incremental, "Incremental innovations are those that reflect a relative small improvement over present product, process, and procedurs these are advance that are little Letter, a little faster. or a little cheaper". Inovasi incremental adalah inovasi yang memberikan dampak kecil pada pengembangan produk yang ada, proses dan prosedur yang sedikit lebih baik, sedikit cepat atau sedikit lebih murah. 
2. Inovasi Distinctive, "Distinctive innovations are those that provide significant advances or improvement, but are not based on fundamentally new technologies or approach", Inovasi distictive menghasilkan pengembangan yang signifikan tetapi tidak berdasarkan pada teknologi baru atau pendekatan baru yangmendasar.

3. Inovasi Breakthrough. Breakthrough innovation, pada definisi ini : are those that are based on fundamentally different technologies and approach, and that allow the performance or function that were relationship not possible, or the pelformance of presently possible function in a manner that is strikingly superior to the old result in significant number of distinctive innovations and in a flood of incremental innovations.

\section{METODE PENELITIAN}

Metode penelitian yang digunakan dalam penelitian ini adalah metode penelitian kualitatif. Metode penelitian kualitatif adalah penelitian yang menekankan pada kualitas dari kesatuan dan pada proses yang tidak diuji atau diukur melalui eksperimen dalam kaitannya dengan kuantitas, jumlah, intensitas, atau frekuensi. Penelitian kualitatif lebih menekan pada kenyataan yang dibangun, hubungan antara peneliti dengan apa yang dipelajari, dan batasan situasi yang membentuk penelitian tersebut (Thoha, 2007).

\section{Pemilihan Informan}

Dalam penelitian kualitatif terdapat dua jenis informan yaitu informan kunci (Expert) dan informan biasa (Ordinary). Pemilihan informan didasari akan latar belakang kemampuan dan keahlian serta kepentingan yang sesuai dengan topik penelitian. Para informan tersebut harus dinilai mampu menjawab pertanyaan dari interview questions dankesesuaian antara latar belakang informan dengan topik permasalahan yang diteliti selanjutnya akan menentukan validitas dari penelitian ini.

Pada penelitian ini, para informan terdiri atas 3 orang informan kunci (Expert) dan 5 orang informan biasa (Ordinary). Informan kunci (Expert) dari penelitian ini terdiri atas:

1. Bapak Iman sebagai Manajer HCD

Manajer divisi HCD merupakan pihak pengelola perusahaan Rabbani yang tentunya mengetahui budaya dan structural organisasi Rabbani. Dengan latar belakang pekerjaan tersebut, informan dinilai dapat menjawab interview quetions dari penelitian ini.

2. Bapak Denny Kosasih sebagai Manajer Marketing

Divisi marketing merupakan pihak yang memiliki pengalaman dalam menangani pemasaran terutama berkaitan dengan inovasi produk dari rabbani, sehingga peneliti menilai informan akan mampu menjawab interview quetions dari penelitian ini. Infoman dari divisi ini terdiri dari manajer dan karyawan.

3. Bapak Didin sebagai Manajer Keuangan Manajer divisi Keuangan merupakan pihak pengelola keuangan perusahaan Rabbani. Dengan latar belakang pekerjaan tersebut, informan dinilai dapat menjawab bagaimana penerapan budaya organisasi Rabbani khususnya pada divisi keuangan.

Untuk 5 orang informan biasa (Ordinary) terdiri dari:

1. Bapak Singgih sebagai staff divisi HCD

2. Laila Rabbaniya sebagai Sales Consultant Muslimah

3. Fitri Damayanti sebagai Sales Consultant Muslimah

4. Mirna Megawati sebagai Sales Consultant Muslimah

5. Gita Yulianty sebagai Sales Consultant Muslimah 


\section{Pengumpulan Data}

\section{Data Primer}

Data primer dalam penelitian ini diperoleh melalui in-depth interview. yaitu proses wawancara secara mendalam (in-depth interview) dengan informan expert dimana selama proses wawancara tersebut direkam dengan mengunakan alat perekam $M p 3$.

Daftar pertanyaan dikategorikan sebagai Semi Structured Qualitative Interview, yang berarti pada saat wawancara, peneliti fokus pada daftar pertanyaan utama yang telah dibuat sebelumnya namun tidak menutup kemungkinan adanya pertanyaan-pertanyaan baru yang muncul yang dapat memperkaya dan memperdalam informasi yang didapatkan ketika wawancara berlangsung.

Proses penelitian ini bersifat flexible dan iterative. Flexible dalam hal ini berarti bahwa sumber data diperoleh dari hasil interview tanpa adanya leading factor yaitu suatu kondisi dimana peneliti dilarang memaksakan atau menuntun jawaban informan sehingga pada akhirnya diharapkan akan diperoleh jawaban yang lebih luas dan mendalam mengenai topik penelitian.

\section{Data Sekunder}

Data sekunder dalam penelitian ini diperoleh melalui perbandingan-perbandingan, dengan membaca literatur, dokumen dan laporan yang berkaitan dengan konsep-konsep mengenai budaya organisasi, konsep mengenai budaya organisasi Islam, Konsep Inovasi, Konsep Inovasi organisasi, dokumen-dokumen perusahaan Rabbani, serta mencari informasi dari jurnal atau paper yang mendukung analisis terhadap Budaya Organisasi Islami dan pengaruhnya terhadap inovasi organisasi pada Rabbani, Bandung.

\section{HASIL PENELITIAN DAN PEMBAHASAN}

Rabbani berdiri sejak tahun 1994 di Bandung dengan menjual berbagai macam buku Islami dan perlengkapan muslim yang tidak diproduksi sendiri oleh Rabbani. Kemudian, pada tahun 1999 Rabbani beralih fokus yaitu menjual produk kerudung instan Rabbani.

Produk ini diterima dikalangan anak muda karena memiliki 3 (tiga) kelebihan yaitu mudah dikenakan, syar'i, tetapi tetap modis. Selain itu, produk kerudung instan ini didorong juga dengan maraknya penggunaan kerudung pada akhir tahun 1980-an.

\section{Budaya Organisasi Rabbani}

\section{Fokus Konsumen / Consumer Focus}

Fokus konsumen memiliki arti bahwa Rabbani menyediakan kebutuhan untuk konsumen. Tujuan Rabbani adalah menjadi Retailer terpercaya dimanapun Rabbani berada dengan memberikan standar yang tinggi untuk produk, jasa pelayanan dan sikap Rabbani kepada seluruh pelanggan.

\section{Fokus Kualitas / Quality Focus}

Fokus kualitas juga memiliki syarat-syarat produk yang layak diproduksi. Terkait kain yang digunakan, beberapa produk menggunakan kain yang tidak umum di pasaran. Dengan demikian, harga cukup tinggi tapi sebanding dengan kualitasnya. Karena Rabbani mengutamakan kualitas untuk konsumen.

\section{Fokus Karyawan / Employes Focus}

Nilai yang ditanamkan dalam Fokus Karyawan adalah bahwa karywan tidak hanya bekerja tetapi juga harus memperhatikan ibadahnya. Rabbani melalukan evaluasi dengan indikatornya yaitu sholat, ibadahnya sunah, puasa, tilawah dan lain-lainnya. Oleh Karena itu 
karyawan tidak hanya memperhatikan pekerjaannya tetapi juga alasan mengapa harus melakukan pekerjaan seperti itu.

Nilai utama ynang ditanamkan pada setiap karyawan Rabbani yang dinamakan Core value Rabbani, terdiri dari:

1. Selalu Bersyukur
a. Totalitas dalam pekerjaan
b. Berfikir Positif
c. Mencintai Pekerjaan
d. Memberikan pelayanan terbaik bagi stake holder
e. Bersikap ihsan dalam bekerja

2. Semangat Pantang Menyerah

a. Selalu memiliki jalan keluar dari setiap masalah dalam pekerjaan

b. Berani menghadapi masalah dan tidak menghindari masalah

c. Memiliki semangat berkompetisi dalam pekerjaan

d. Tidak ada pekerjaan yang tidak bisa diselesaikan

e. Berpihak kepada perusahaan

3. Perbaikan Berkesinambungan

a. Selalu berfikir Kreatif dan Inovatif

b. Berorientasi zero deffect

c. Selalu ada terobosan baru

d. Menjalankan Standar Operasional Prosedur (SOP) perusahaan dengan sepenuh hati

e. Semua pekerjaan yang dilakukan harus by design dan barometer yang jelas

f. Berbicara dengan fakta dan data sesuai dengan ratifikasi perusahaan (pengesahan)

4. Peduli Dalam Setiap Keadaan

a. Menjaga asset perusahaan

b. Peduli dengan tempat bekerja dan lingkugannya

c. Selalu Berusaha untuk mencegah kerugian perusahaan

d. Sekecil apapun masalah tidak diangap sepele apalagi diremehkan
5. Memiliki Tanggung Jawab yang Tinggi

a. Bertanggung jawab untuk menyelesaikan pekerjaan sampai tuntas

b. Berani mengambil resiko baik material maupun non material

c. Memberikan kemampuan yang terbaik untuk perusahaan

d. Membela (advokasi) perusahaan dalam kondisi apapun selama tidak bermaksiat kepada Allah Swt.

\section{Kondisi Budaya Organisasi Islami pada Rabbani}

Budaya Rabbani terbentuk dari pemahaman pendiri Rabbani yang lahir dari aktvitas dakwah sebagai aktivis dakwah yang terbina dalam kondisi ruhiyah untuk syiar besar. Sehingga yang menjadi landasan ketika membangun bisnis adalah nilai-nilai tersebut. Tagline yang digunakan berupa "mengkerudungkan dunia" karena itu bentuk syiar bagaimana Islam itu dapat diterima oleh banyaknya muslimah yang dapat diimplementasikan dalam berpakaian muslimah. Dan karena pemikiran pemilik dari Rabbani yang memang aktivis dakwah sehingga hal yang terkait dengan Rabbani tidak hanya berjualan atau berbisnis.

Jadi intinya, bahwa pemilik Rabbani terbina dalam lembaga dakwah sehingga pada langkah geraknya mengarah pada Allah (dakwah).

Tujuh hal yang dibina oleh Rabbani yaitu;

a. Sholat Qiyamul Lail

b. Sholat Subuh berjamaah (bagi pria)

c. Tilawah

d. Sholat dhuha

e. Istighfar

f. Shaum sunah

g. Menjaga wudhu selama bekerja.

\section{Penerapan Budaya Organisasi Islam Rabbani pada Fungsi Bisnis}

Pemasaran, hal ini terkait produk, harga, tempat dan promosi. Produk yang dijual Rabbani awalnya berupa buku islami kemudian beralih 
pada produk kerudung instan, masih berupa produk yang bersifat islami. Kemudian harga yang ditawarkan masih pada kelas mengengah ke atas, sehingga menjadi pertimbangan tersendiri untuk menuju "mengkerudungkan dunia", sehingga produk dalam dijamah oleh kelas menengah ke bawah.

Selain hal itu, Rabbani memiliki beberapa kerja sama dengan supplier agar produk Rabbani terkumpul dan tersebar ke 151 cabang yang 4\%nya milik mitra dan sisanya adala milik pemilik pribadi. Berkaitan dengan promosi, Rabbani melalukannya melalui online, majalah dan spanduk. Spanduk Rabbani memiliki ciri khas dengan kata-kata ekstrim yang sedang hangat di masyarakat dengan tujuan menyadarkan masyarakat mengenai isu tersebut.

Human Capital Development (HCD), di Holding Rabbani, divisi HCD berfungsi mendukung sepenuhnya kegiatan pemasaran dan timnya, dan keuangan untuk melalukan fungsinya dengan menyediakan SDM yang berkualitas. Pada HCD, terjadi perubahan struktur jabatan yang cepat mencapai 2 kali dalam setahun. Hal ini menunjukkan Rabbani cenderung berani melakukan perubahan untuk memperbaiki kinerja organisasinya.

Kemudian dampak dari perubahan struktur yang cepat mengakibatkan inovasi organisasi seperti rencana didirikannya divisi Training Development, menyusun Pakta Integritas yang merupakan susuna 6 indikator pemecatan karyawan untuk mengetatan nilai-nilai Islam yang diterapkan Rabbani.

Terkait budaya dan kepemimpinan, pemilik Rabbani menjadi titik sentral kepemimpinan dimana setiap keputusan terpusat padanya. Seperti perubahan struktur secara cepat yang sudah menjadi budaya dalam organisasi. Budaya organisasi ini juga dipegaruhi oleh latar belakang pemilik Rabbani yang seorang aktivis dakwah.

HCD juga turut mengawasi penerapan nilainilai Islami Rabbani yang ditanamkan oleh pemilik. Serta memfasilitasi, menitoring dan koordinasi segala aktivitas sumber daya manusia dalam perusahaan.

Berkaitan dengan PHK, Rabbani menerapkan 6 Pakta integritas seperti korupsi, EHS (Employee Health Safety). Kasus lainnya, apabila karyawan memasalahkan nilai-nilai utama yang diterapkan Rabbani sehingga karyawan tersebut memiliki pola pikir yang berbeda dengan Rabbani, maka PHK akan dilakukan oleh Rabbani.

Keuangan, program terkaitan keuangan yaitu zakat, CSR, dan pencegahan korupsi. Zakat mall dikeluarkan setiap tahun oleh perusahaan, sedangkan untuk infaq dan sedekah terutama dilakukan ketika bulan puasa.

Sejak tahun 2011, Rabbani telah membentuk CSR yang dikelola oleh divisi operasional. Hal ini didasari pemahaman Rabbani bahwa sebaikbaiknya manusia adalah yang bermanfaat bagi orang lain. Secara konkrit kegiatan CSR berupa membangun wc umum yang bekerja sama dengan lembaga profesional. Bentuk lainnya berupa pemberdayaan anak jalanan, pengembangan dana pendidikan berupa beasiswa yang sejauh ini diperuntukan bagi Anak-anak ustad yang membutuhkan dan direkomendasikan. Terakhir Rabbani memiliki rencana untuk membuat lembaga pendidikan dengan perkembangan terbaru sudah sampai pada tahap mengakuisisi TK.

Dalam hal pencegahan terjadinya korupsi, divisi keuangan memiliki SOP tersendiri. Bagian kasir memiliki prosedur dalam membuat laporan, kemudian menyetorkan uang. Dalam 1 hari jika bagian kasir tidak menyetorkan uang, maka akan kena teguran karena melanggar SOP. Jika kemudian dilakukan penyelidikan dan terbukti terjadi penyelewengan dana, maka akan langsung di PHK.

Dengan pemanfaatan IT pada divisi keuangan yang mencakup ke store-store, sehingga dengan sistem tersebut dapat diketahui dengan mudah berapa omset yang diperoleh 
ditiap store. Dilengkapi dengan adanya berita acara, memudahkan Rabbani untuk mengethuia aktivitas keuangan yang terjadi. Pada prinsipnya, walaupun sudah cukup baik sistem yang dibangun, namun Rabbani menyadari masih banyak kelemahan dan tetap terus memperbaiki sistem yang ada.

\section{Penerapan Budaya Organisasi Islam Rabbani dalam Mendorong Inovasi Organisasi}

\section{Pengembangan Inovasi Perusahaan}

Rabbani selalu cenderung sering melakukan pengembangan struktur, sebagai wujud diversifikasi perusahaan. Seperti rencana pengembangan bisnis properti (rumah zakat dan rumah juara untuk program pendidikan dan kesehatan), Inhouse Training (pengembangan SDM untuk menjadi tim EO untuk pelayanan eksternal).

Selain itu, Rabbani konsisten mengikuti perubahan pemasaran dan penjualan yang dinamis sehingga berani berimprovisasi, kreatif dan inovatif. Sejalan dengan budaya organisasi yang menyukai perubahan dan pembelajaran.

Hal ini ditunjukkan pula dengan adanya kepercayaan pengambilan keputusan yang diberikan kepada tim RnD oleh pemilik Rabbani. Selain itu, ada beberapa faktor yang mempengaruhi organisasi dalam mengimplementasikan sebuah inovasi (Lalangiran, 2012):

\section{a. Life Cycle}

Seperti halnya manusia, suatu organisasi juga mengalami siklus hidup dengan berbagai tingkatan dan perkembangan (Sperry, Mickelson, dan Hunsaker, 1977). Tingkat perkembangan organisasi pada saat inovasi diajukan akan mempengaruhi nilai perubahan organisasi.

b. Strategic Plan

Salah satu aspek yang mendukung implementasi inovasi adalah adanya rencana strategis organisasi. Ketika inovasi selaras dengan rencana strategi organisasi, maka pelaksana inovasi mempunyai tambahan argument kuat untuk mendapatka dukungan manajemen dan meyakinkan kelompok user.

\section{c. External Conditions}

Akan selalu ada kondisi eksternal yang mempengaruhi organisasi. Hal-hal semacam ini harus juga dipertimbangkan ketika mengaplikasikan sebuah inovasi. Karena hal tersebut akan memberikan pengaruh yang signifikan secara tidak langsung terhadap jalannya inovasi dan organisasi.

\section{Pengembangan Budaya Organisasi}

Untuk bisa menjadi sebuah perusahaan yang maju dan besar, Rabbani memiliki 3 prinsip yang selalu dicoba untuk diterapkan, yaitu VSL terdiri dari Value, berkaitan dengan core value, atau culture. Kemudian Sistem, yaitu dengan membangun sistem, prosedur, SOP, konsekuensi, modul dan lain-lain yang dapat mendukung kinerja perusahaan. Yang ketiga Leader, dengan gaya kepemimpnan yang baik diharapkan mampu mengerakkan semua elemen yang ada diorganisasi. Dari ketiga prinsip tersebut, kepemimpinan ini lah yang akan sangat menentukan keberhasilan perusahaan. Rabbani sampai saat ini masih terus memperbaiki dan mengembangkan 3 prinsip tersebut dalam penerapannya.

Sebagaimana yang telah diijelaskan pula, Rabbani senantiasa melakukan evaluasi terhadap nilai-nilai budaya organisasinya. Misalnya dengan menambah amalan yaumiah yang semula 5 poin menjadi 7 poin. Poin yang ditambahkan tersebut antara lain kewajiban untuk menghafal ayat Alquran dan sholat subuh berjamaah khusus bagi karyawan laki-laki. 


\section{SIMPULAN}

Berdasarkan hasil penelitian dan pembahasan dapat ditarik kesimpulan sebagai berikut:

1. Penerapan budaya organisasi islami pada Perusahaan Rabbani Bandung telah berjalan dengan konsisten dan begitu dinamis. Hal ini dapat dilihat dari perilaku karyawan yang senantiasa mengikuti nilai-nilai yang berlaku di Rabbani. Mulai dari amalan yaumiyah yang rutin di eveluasi setiap pagi hingga bagaimana hubungan antar karyawan laki-laki dan perempuan. Nilai-nilai Islami juga dapat dilihat pada produk-produk yang dihasilkan, suasana toko dan kantor, cara berpakaian karyawan, serta strategi promosi yang dilakukan cenderung unik dengan membawa nilai-nilai Islam.

2. Inovasi organisasi yang dilakukan oleh Rabbani Holding Bandung dilakukan dengan begitu cepat dan berkesinambungan. Rabbani memiliki keberanian dalam melakukan inovasi organisasinya karena faktor kepemimpinan dan budaya yang kuat, serta yang memiliki kelenturan struktur sehingga begitu fleksibel dalam menghadapi perubahan. Dengan berbagai rencana pengembangan organisasi yang dirancang dengan pemikiran yang matang, secara nyata dirintis dan dikembangkan untuk perluasan bisnis Rabbani itu sendiri.

3. Pada Rabbani Holding ditemukan bahwa budaya organisasi islami memiliki peran besar dalam mendorong inovasi organisasi. Dapat dilihat bahwa Rabbani dengan pemahaman nilai agama terus melalukan perubahan ke arah yang lebih baik. Rabbani memiliki visi ke depan terkait dengan penanaman nilai-nilai Islam yang mendunia. Untuk mencapai tujuannya tersebut, Rabbani secara konsisten menerapkan nilai Islami untuk mendorong perubahan sistem organisasi agar dapat menajdi perusahaan yang besar dan dinamis.

\section{DAFTAR PUSTAKA}

Abdul Hakim. 2012. The Implementation Of Islamic Leadership \& Islamic Organizational Culture \& Its Influence On Islamic Working Motivation and Islamic Performance PT Bank Mu'amalat Indonesia Tbk. Employee in the Central Java. Asia Pasific Management Review 17 (1)(2012) 77-90.

Caputo, A.C., et al. 2002. "A Methodological Framework for Innovation Transfer To SMEs",Industrial Management + Data Systems, ABI/INFORM Global pg. 27

Churchill, Gilbert A. and Iacobucci, D. 2005. Marketing Research: Methodological Foundations, $9^{\text {th }}$ edition. Ohio. SouthWestern Thomson Corporation

Denzin, N. K. \& Lincoln, Y. S. 1994. Handbook of Qualitative Research, Sage Publications, Thousand Oaks.

E.M. Rogers. 1983. Diffusion of Innovation. Free Press, New York.

Malhotra, N. 2004. Marketing Research $4^{\text {th }}$ edition. New Jersey. Pearson Education.

Morris, Desmond. 1977. MANWATCHING-A Field Guide To Human Behavior. New York: Harry N. Abrams, Inc. New York,U.S.A

Sugiyono. 2004. Metode Penelitian Administrasi. Bandung: Alfa Beta.

Thoha, N. Bickley, M. \& Whiteley, A. 2006. "HRM Transition in Indonesian Companies: Linear and Non-Linear Approaches", International Review of Business Research Papers. Vol 2. No. 1 May pp. 1 -15.

Thoha. 2007. Power Point: Grounded Theory and Grounded Research, Sampoerna SBM ITB.

Umberto Eco. 1976. A Theory of Semiotics. Bloomington: Indiana University Press. 


\section{Rujukan Elektronik}

http://www.beritasatu.com/gaya-hidup/119248-

jakarta-islamic-fashion-week-ingin-

menjadi-parameter-industri-busana-

muslim-indonesia.html_diakses pada 2 April 2013

http://wolipop.detik.com/read/2013/06/01/0933

14/2262065/233/nuniek-mawardi-desainbusana-muslim-terinspirasi-motif-flanelskotlandia_diakses pada 2 April 2013

http://lalangiran.wordpress.com/2012/02/19/im plementasi-teknologi-kinerja-dalam-

organisasi-part-2/_diakses pada 2 April 2013

www.rabbani.co.id_diakses pada 6 April 2013 